\title{
Atividade antimicrobiana das pastilhas de Paraformaldeído reproduzindo as condições de uso nas instituições de saúde do Brasil*
}

\author{
PARAFORMALDEHYDE TABLETS MICROBIOLOGICAL ACTIVITY REPRODUCING THE USE CONDITIONS \\ OF THE BRAZILIAN HEALTH INSTITUTIONS
}

\section{ACTIVIDAD ANTIMICROBIANA DE LAS PASTILLAS DE PARAFORMALDEHÍDO REPRODUCIENDO LAS CONDICIONES DE USO EN LAS INSTITUCIONES DE SALUD DEL BRASIL}

\section{Kazuko Uchikawa Graziano', Luciene Figueiredo²}
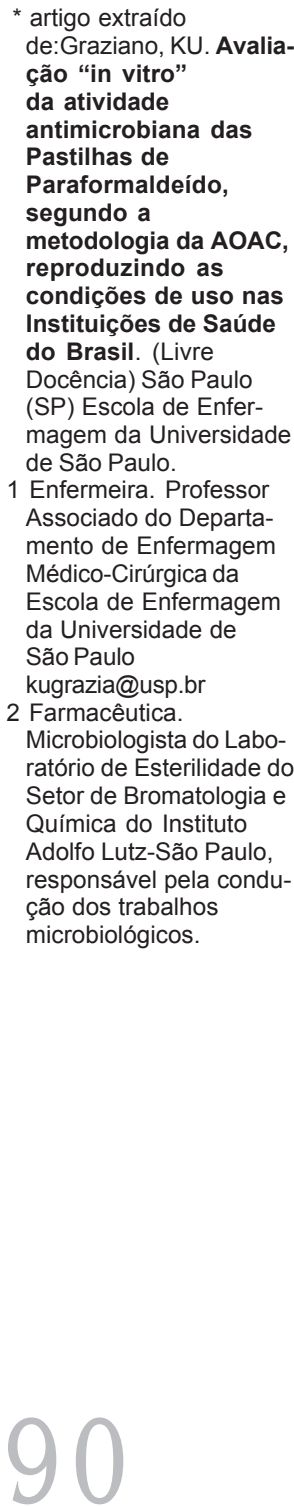

Rev Esc Enferm USP 2003; 37(1): 90-6.

\begin{abstract}
RESUMO
A atividade antimicrobiana das Pastilhas de Paraformaldeído, reproduzindo as condições de uso das Instituições de Saúde do Brasil (sem o aquecimento, semo acréscimo da umidade relativa, a $5 \%$, por um período longo de exposição de 12 horas), foi avaliada "in vitro" por meio do monitoramentomicrobiológico, segundo a metodologia da $A O A C$, adotadaoficialmentepeloMinistério da Saúde do Brasil para o registro dessa categoria de produtos. Os resultados dos experimentos refutaram a ação esterilizante das Pastilhas deParaformaldeído nestas condições. Diante destes resultados, realizou-se, então, os testes paraavaliação desinfetantedo produto utilizando-seo Método de Diluição de Uso, preconizada pela $A O A C$, adaptado para produtos gasosos, contra os microrganismos teste padronizados Staphylococcus aureus (ATCC $n^{\circ}$. 6538), Samonella choleraesuis $\left(A T C C n^{\circ} .10708\right) e$ Pseudomonas aeruginosa $\left(A T C C n^{\circ}\right.$. 15442). Nestes experimentos, os resultados das culturas mostraram-se $100 \%$ negativos contra todas as bactérias testadas inferindo-seindiciosdeatividade desinfetantedealtonível.
\end{abstract}

\section{PALAVRAS-CHAVE}

Pastilhas de Paraformaldeído, Esterilização química; Desinfecção dealtonivel; Centralde Materiale Esterilização; Metodologiada $A O A C$.

\section{SUMMARY}

The sterilizing activity of Parafolmaldehyde Tablets reproducing the conditions of use in the Brazilian health Institutions (without the heating, without increment of the relative humidity, in $0.5 \%$, even for a long period of exhibition of 12 hours) was evaluated "in vitro" by microbiologic monitoring, according to the methodology of the AOAC, officially adopted by the Brazilian Health Ministry for registration of that category of products. The results of the experiments refuted the sterilizing action of Parafolmaldehyde Tablets in this conditions. Thus, it was evaluated the disinfectant action of the product using the vegetative bacterias by Use Dilution Method, preconized for $A O A C$ and adapted for gaseous products, against the tests microorganisms standardized Staphylococcus aureus (ATCCn. 6538), Samonella choleraesuis (ATCC n. 10708) and

Pseudomonas aeruginosa (ATCC $n$. 15442). In these experiments, the results of the cultures showed 100\% negative against all the tested bacterias inferring indications of disinfectant activity of high level action.

\section{KEYWORDS}

Paraformaldehydetablets; Chemical sterilization; higt level of desinfectantactivity; $A O A C$ metodology.

\section{RESUMEN}

Laactividad antimicrobiana delas PastillasdeParaformaldehído, reproduciendolas condiciones de uso en las Instituciones de Salud del Brasil (sinel calentamientoyaumento dela humedadrelativa, en un porcentaje del $0,5 \%$, pese al largo periodo de exposición de 12 horas), fue evaluada "in vitro" pormedio del monitoramientomicrobiológico, segín lametodologíadela $A O A C$, adoptadaoficialmenteporel Ministerio de Salud del Brasil parael registro de esa categoría de produtos. Los resultados de los experimentos refutaron laacción esterilizante delas PastillasdeParaformaldehídoen las condiciones estudiadas. Frente a estos resultadosserealizó, entonces, los test paraevaluacióndesinfectantedel produtoutilizándoseel Métodode Dilución de Uso, preconizada por la $A O A C$, adaptado para productos gaseosos, contra los microorganismos test patronizados Staphylococcus aureus $(A T C C n$. 6538), Samonellacholeraesuis(ATCC $n^{\circ}$. 10708) e Pseudomonas aeruginosa (ATCCn . 15442). En estos experimentos, los resultados delos cultivos se mostraron 100\% negativos contra todas las bacterias probadas. Los resultados microbiológicosnos permiten inferir quelas Pastillas de Paraformaldehido mostró indicios de actividad desinfectantedealtonivel.

\section{PALABRAS- CLAVE}

Pastillas de Paraformaldehído, Esterilización química; Desinfección de alto nivel; Centro de Material y Esterilización; 
A esterilização dos artigos críticos e, se possível, dos semi-críticos, é prática de comprovada eficácia na prevenção e controle de infecções hospitalares ${ }^{(1)}$. Embora o processo de esterilização que oferece maior segurança seja o da autoclavação com vapor de água saturado e sob pressão, a escolha depende da natureza do material a ser esterilizado. Os artigos termossensíveis são submetidos à esterilização em autoclaves de óxido de etileno, de gás plasma de peróxido de hidrogênio, de vapor de baixa temperatura e formaldeído; em soluções de ácido peracético, automatizado ou manual; em soluções de glutaraldeído ou formaldeído em condições adequadas ${ }^{(2-4)}$.

Refletindo as dificuldades existentes em relação a recursos para esterilização, uma das autoras realizou um levantamento junto às istituições de saúde do Brasil e constatou que em 253 centrais de materiais, de diferentes estados brasileiros, ocorre o processamento de artigos odonto-médico-hospitalares termossensíveis, bem como alguns termorresistentes considerados delicados, por meio de pastilhas de Paraformaldeído, sem o uso do aquecimento e da umidade relativa, com quantificação e período de exposição variáveis. Sabe-se que estas condições são desfavoráveis à ação antimicrobiana das Pastilhas de Paraformaldeído, e a literatura reforça a necessidade dessas variáveis físicas para a ação antimicrobiana do gás sublimado das mesmas ${ }^{(5-7)}$. Existem publicações que relataram o crescimento dos esporos do Bacillus subtilis, como microrganismo teste, quando o aquecimento não fazia parte do processo de esterilização ${ }^{(8-9)}$. Outro fato que reforça as desvantagens da não utilização do aquecimento durante o processamento de artigos críticos usando as Pastilhas de Paraformal-deído, é a constatação de que os níveis de liberação do gás formaldeído, à temperatura ambiente, é inferior àqueles atingidos quando aquecidas a $50^{\circ} \mathrm{C}$, independente do intervalo de tempo de exposição ${ }^{(10)}$.

No Brasil, o registro de produtos com finalidade antimicrobiana deve atender a normas regulamentares, que incluem a sua análise microbiológica prévia ${ }^{(11)}$. O objetivo desta investigação foi verificar o nível microbicida atingido pelas pastilhas de paraformaldeído quando o aquecimento e a umidade não são incluídos nos processos, utilizando-se as pastilhas de Paraformaldeído à concentração de $0,5 \%$ e exposição ao gás por 12 horas.

\section{MATERIAL E MÉTODO}

\section{Local do estudo}

A pesquisa foi desenvolvida no Laboratório de Esterilidade do Setor de Bromatologia e Química do Instituto Adolfo Lutz, localizado no município de São Paulo.

\section{Material}

Pastilhas de Paraformaldeído (MIAKO DO BRASIL - Indústria e Comércio Ltda. São Paulo, SP) contendo cerca de $0,5 \mathrm{~g}$ do princípio ativo / pastilha.

Concentração testada por volume do recipiente (marmita de alumínio c/ 17x $11 \times 4 \mathrm{~cm}$ ): $0,5 \mathrm{~g} / \mathrm{cm}^{3}\left(0,5 \mathrm{~g}\right.$ para cada $100 \mathrm{~cm}^{3}$ do volume do recipiente).

\section{Tempo de exposição: 12 horas.}

\section{Teste para avaliação esterilizante}

Foi realizado segundo a técnica da Association of Official Analyptical Chemistis $^{(12)}$ utilizada pelo Instituto Nacional de Controle de Qualidade em Saúde ${ }^{(13)}$.

Empregou-se 120 cilindros de porcelana adquiridos da Fischer Scientific Co., ${ }^{\circ} 7.907$ como carreadores para cada microrganismo teste (Bacillus subtilis, ATCC 19.659 e Clostridium sporogenes, ATCC 3.584). Em todos os experimentos, os esporos dessecados sobre os carreadores foram reidratados com água destilada estéril, utilizando-se 20 $\mathrm{ml}$ para cada lote com 6 carreadores. A seguir, foram drenados por 20 minutos, em placas de Petri contendo papel de filtro.

Como meios de cultura e subcultura dos microrganismos testes, foi empregado o tioglicolato fluido com sulfito de sódio na concentração de $0,1 \%$ como neutralizante da ação residual do formol.

\section{Teste para avaliação bactericida}

Foi realizado segundo o Método da Diluição de Uso, adaptado para produtos gasosos de acordo com a técnica da Association of Official Analyptical Chemistis ${ }^{(12)}$ utilizada pelo Instituto Nacional de Controle de Qualidade em Saúde ${ }^{(13)}$.

Empregaram-se 60 cilindros de aço inoxidável tipo 304, SS18-8, polidos, adquiridos
Atividade antimicrobiana das Pastilhas de Paraformaldeído reproduzindo as condições de uso nas Instituições de Saúde do Brasil 
Kazuko Uchikawa Graziano Luciene Figueiredo da Fischer Scientific Co. como carreadores para cada microrganismo teste (Staphylococcus aureus ATCC ${ }^{\circ} .6538$, Salmonella choleraesuis, ATCC n ${ }^{\circ} .10708$ e Pseudomonas aeruginosa, $\mathrm{ATCC} \mathrm{n}^{\circ}$. 15442).

Como meios de cultura e subcultura dos microrganismos testes, foi empregado o caldo nutriente com sulfito de sódio na concentração de $0,1 \%$ como neutralizante da ação residual do formol.

Os cilindros contaminados com os microrganismos testes, após o término do tempo de secagem, foram colocados em recipientes de alumínio (marmitas) com 9 Pastilhas de Paraformaldeído $(0,5 \%)$ espalhadas ao seu redor, sem umidade adicional. O recipiente foi vedado com fita crepe e mantido à temperatura ambiente do laboratório por 12 hs. Após o tempo de contato os cilindros foram transferidos para o meio de cultura. Os tubos das duas séries ( $1^{\mathrm{a}}$ e $2^{\mathrm{a}}$ subcultura) foram incubados a $36 \pm 1^{\circ} \mathrm{C}$ por 21 dias nos testes de esterilização e $48 \mathrm{hs}$ nos testes de ação bactericida, sendo então observada a presença ou a ausência de crescimento.

Nos testes de avaliação esterilizante, os tubos com carreadores onde não foi observado o crescimento (ausência de turbidez) foram submetidos a um choque térmico durante 20 minutos a $80^{\circ} \mathrm{C}$ e reincubados por 72 horas a $37^{\circ} \mathrm{C}$, registrando-se então os resultados finais como presença ou ausência de crescimento

Nos testes de avaliação bactericida, as culturas teste foram controladas quanto à resistência ao fenol, como descrito no método do coeficiente fenólico (Association of Official Analyptical Chemistis, 1995), nas diluições 1:60 e 1:70 (S.aureus), 1:80 e $1: 90$ (P.aeruginosa) e 1:90 e 1:100 (S.choleraesuis). Os resultados foram considerados satisfatórios quando os microrganismos sobreviveram após 5, 10 e 15 minutos de contato com as diluições mais altas e não sobreviveram após 15 minutos de contato com as diluições mais baixas.

Nos testes de avaliação esterilizante, a viabilidade dos microrganismos testes carreados pelos penicilindros foram validados frente ao $\mathrm{HCl}$ na concentração $2,5 \mathrm{~N}$, submetendo-se ao contato do ácido por 2, 5, $10 \mathrm{e}$ 20 minutos. Para a confiabilidade do inóculo utilizado, os esporos tiveram que resistir por 2 minutos, no mínimo, podendo resistir por mais de 20 minutos.

\section{RESULTADOS}

Os resultados da atividade esporocida para comprovação da atividade esterilizante são apresentados nos Quadros 1 e 2

Quadro 1 - Atividade esporocida das Pastilhas de Paraformaldeído a $\mathbf{0 , 5} \%$ frente a esporos de Bacillus subtilis à temperatura ambiente, por $12 \mathrm{~h}$ de exposição, sem adição da umidade relativa, avaliada pela metodologia da AOAC. São Paulo, 1999

\begin{tabular}{|c|c|}
\hline CARREADORES & $\begin{array}{c}\text { ATIVIDADE } \\
\text { ESPORICIDA* }\end{array}$ \\
\hline Sem crescimento & Subculturas \\
Com crescimento & $120 / 120$ \\
& $0 / 120$ \\
\hline
\end{tabular}

${ }^{*} N^{o}$ de tubos com ou sem crescimento/ $N^{o}$ de tubos testados

Controle positivo da viabilidade do inóculo:

Período de contato com $\mathrm{HCl}$

$\begin{array}{llll}2^{\prime} & 5^{\prime} & 10^{\prime} & 20^{\prime} \\ S R & S R & S R & S R \\ ++ & ++ & + \text { - } & \text { - }\end{array}$

Quadro 2 - Atividade esporocida das Pastilhas de Paraformaldeído a $0,5 \%$ frente aos esporos de Clostridium sporogenes à temperatura ambiente, por $12 \mathrm{~h}$ de exposição, sem adição da umidade relativa, avaliada pela metodologia da AOAC. São Paulo, 1999

\begin{tabular}{|c|c|}
\hline CARREADORES & $\begin{array}{c}\text { ATIVIDADE } \\
\text { ESPORICIDA* }\end{array}$ \\
\hline Sem crescimento & Subculturas \\
Com crescimento & $42 / 120$ \\
& $78 / 120$ \\
\hline
\end{tabular}

* $N^{o}$ de tubos com ou sem crescimento/ $N^{o}$ de tubos testados

Positivo da viabilidade do inóculo:

Período de contato com $\mathrm{HCl} \quad 2^{\prime} \quad 5^{\prime}$

$10^{\prime} \quad 20^{\prime}$

$S R \quad S R \quad S R \quad S R$

$++\quad-. \quad-$

Todos os tubos de subcultura do Bacillus subtilis apresentaram crescimento negativo durante os 21 dias em que estiveram incubados. Porém, após o choque térmico a $80^{\circ} \mathrm{C}$ por 20 minutos e $72 \mathrm{~h}$ de reincubação a $37^{\circ} \mathrm{C}$, houve recuperação do Bacillus subtilis em 6 tubos de subcultura $(2,5 \%)$. Este fato mostrou uma característica particular do 
Bacillus subtilis que foi a dormência prolongada dos microrganismos em questão quando "estressados" frente à ação do Paraformaldeído.

Diante destes resultados dos testes microbiológicos, refutou-se a ação esterilizante das Pastilhas de Paraformaldeído a 0,5\% nas condições de uso à temperatura ambiente por $12 \mathrm{~h}$ de exposição, sem a adição da umidade relativa.

Neste estudo, os esporos do Clostridium sporogenes apresentaram maior resistência ao formaldeído gasoso do que os esporos do Bacillus subtilis, ao contrário dos dados observados por pesquisas de Mecke ${ }^{(6)}$.

Apesar dos objetivos do presente trabalho restringirem as condições dos experimentos às formas mais freqëntes de uso das Pastilhas de Paraformaldeído pelos Estabelecimentos de Saúde brasileiros $(0,5 \%$, sem aquecimento, na ausência de umidificação adicional e por 12 horas de exposição) realizaramse também testes esporocidas numa quantidade maior de Pastilhas de Paraformaldeído, sendo escolhida a quantificação de 3\% (48 pastilhas para o volume dos recipientes usados nos experimentos) preconizada por Graziano $^{(14)}$.

Mesmo com o aumento da quantificação das Pastilhas de Paraformaldeído (de 9 pastilhas para 48 para cada volume do recipiente usado) houve recuperação tanto do Bacillus subtilis (4 tubos com crescimento/16 tubos testados) quanto do Clostridium sporogenos (4 tubos com crescimento/120 tubos testados) com uma semana de incubação.

Os tubos referidos como contaminados, bem como aqueles que mostraram crescimento de bacilos e clostrídeos, foram examinados quanto às seguintes características: morfologia celular (coloração de Gram) e presença de esporos (coloração de Wirtz).

Diante desses resultados, refutar simplesmente a possibilidade de utilizar as Pastilhas de Paraformaldeído a $0,5 \%$, sem aquecimento e umidificação adicional como esterilizante, deixou uma lacuna para a questão: e contra os microrganismos não esporulados? Será que a ordem decrescente de resistência dos diversos grupos de microrganismos aos germicidas químicos, teoricamente definida por Spaulding ${ }^{(15)}$, pode ser simplesmente transposto? O referido autor propôs a divisão dos níveis de ação germicida a fim de operacionalizar as ações de esterilização e desinfecção dos artigos odonto-médico-hospitalares. A ordem decrescente de susceptibilidade está categorizada na seguinte seqüência: prionsP esporos bacterianosP micobactériasP vírus não lipídicos ou pequenosP fungosP bactérias vegetativasP vírus lipídicos ou de tamanho médio.

$\mathrm{Na}$ tentativa de conhecer mais um pouco da ação microbiocida do Paraformaldeído, optou-se por estudar a ação bactericida deste agente químico nas condições mais freqüentes de utilização das Pastilhas de Paraformaldeído nas Instituições de Saúde Brasileiras.

Os resultados dos testes bactericidas estão apresentados nos quadros 3 a 4.

Quadro 3 - Atividade bactericida das Pastilhas de Paraformaldeído a $0,5 \%$ sobre Staphylococcus aureus (ATCC $n^{\circ}$. 6538) à temperatura ambiente, por $12 \mathrm{~h}$ de exposição, sem umidade relativa adicional avaliada pela metodologia da AOAC. São Paulo, 1999

\begin{tabular}{|c|c|c|}
\hline \multirow{2}{*}{ CARREADORES } & \multicolumn{2}{|c|}{ ATIVIDADE } \\
& \multicolumn{2}{|c|}{ BACTERICIDA* } \\
\hline & $1^{\text {a }}$ Subculturas & $2^{\text {a }}$ Subculturas \\
Sem crescimento & $60 / 60$ & $60 / 60$ \\
Com crescimento & $0 / 60$ & $0 / 60$ \\
\hline
\end{tabular}

${ }^{*} N^{o}$ de tubos com ou sem crescimento/ $N^{o}$ de tubos testado.

Controle positivo da viabilidade do inóculo:

$$
\begin{aligned}
& \text { Teste do Fenol a 5\% : } \quad \text { Staphylococcus aureus } \\
& 1: 60 \quad 1: 70 \\
& 5^{\prime}=(+) \quad 5^{\prime}=(+) \\
& 10^{\prime}=(-) \quad 10^{\prime}=(+) \\
& 15^{\prime}=(-) 15^{\prime}=(+)
\end{aligned}
$$

Os resultados do teste fenol a $5 \%$ foram satisfatórios para S.aureus e S.choleraesuis, mas não foi para $\boldsymbol{P}$.aeruginosa pois não apresentou crescimento após 15 minutos na diluição mais alta (1:90) .

No controle negativo os resultados foram satisfatórios frente aos três microrganismos testes, tendo sido recuperados todos os 10 cilindros contaminados com cada microrganismo.

O controle de viabilidade foi satisfatório para os três microrganismos, pois houve cres-
Atividade antimicrobiana das Pastilhas de Paraformaldeído reproduzindo as condições de uso nas Instituições de Saúde do Brasil 
Kazuko Uchikawa Graziano Luciene Figueiredo
Quadro 4 - Atividade bactericida das Pastilhas de Paraformaldeído a $0,5 \%$ sobre Samonella choleraesuis (ATCC no. 10708) à temperatura ambiente, por $12 \mathrm{~h}$ de exposição, sem umidade relativa adicional avaliada pela metodologia da AOAC. São Paulo, 1999

\begin{tabular}{|c|c|}
\hline Teste do Fenol a 5\%: & Staphylococcus aureus \\
\hline $1: 60$ & $1: 70$ \\
\hline $5^{\prime}=(+)$ & $5^{\prime}=(+)$ \\
$10^{\prime}=(-)$ & $10^{\prime}=(+)$ \\
$15^{\prime}=(-)$ & $15^{\prime}=(+)$ \\
\end{tabular}

* $N^{o}$ de tubos com ou sem crescimento/ $N^{o}$ de tubos testados

Controle positivo da viabilidade do inóculo:

Teste do Fenol a 5\% :Salmonella choleraesuis

$$
\begin{aligned}
& 1: 90 \quad 1: 100 \\
& 5^{\prime}=(+) 5^{\prime}=(+) \\
& 10^{\prime}=(+) 10^{\prime}=(+) \\
& 15^{\prime}=(-) 15^{\prime}=(+)
\end{aligned}
$$

Quadro 5 - Atividade bactericida das Pastilhas de Paraformaldeído a $\mathbf{0 , 5 \%}$ sobre Pseudomonas aeruginosa (ATCC no. 15442) à temperatura ambiente, por $12 \mathrm{~h}$ de exposição, sem umidade relativa adicional, avaliada pela metodologia da AOAC. São Paulo, 1999

\begin{tabular}{|c|c|c|}
\hline \multirow{2}{*}{ CARREADORES } & \multicolumn{2}{|c|}{ ATIVIDADE } \\
& \multicolumn{2}{|c|}{ BACTERICIDA* } \\
\hline & $1^{\text {a }}$ Subculturas & $2^{\text {a }}$ Subculturas \\
Sem crescimento & $60 / 60$ & $60 / 60$ \\
Com crescimento & $0 / 60$ & $0 / 60$ \\
& & \\
\hline
\end{tabular}

* $N^{o}$ de tubos com ou sem crescimento/ $N^{o}$ de tubos testados Teste do Fenol a 5\%: Pseudomonas aeruginosa

$$
\begin{aligned}
& 1: 80 \quad 1: 90 \\
& 5^{\prime}=(-) \quad 5^{\prime}=(+) \\
& 10^{\prime}=(-) \quad 10^{\prime}=(+) \\
& 15^{\prime}=(-) \quad 1 \quad 5^{\prime}=(-)
\end{aligned}
$$

cimento para cada um dos três cilindros que foram retirados da placa antes de entrarem em contato com o paraformaldeído.

Sintetizando os resultado dos testes bactericidas, os achados foram satisfatórios para os três microrganismos teste , não tendo sido observado nenhum tubo de crescimento para os 60 cilindros utilizados.

Sabe-se que a desinfecção de alto nível, além de garantir a destruição de todas as formas vegetativas de microrganismos bacterianos, deve incluir a destruição de alguns esporos. Assim sendo, apesar da limi- tação desse estudo por não estar nele incluida a avaliação microbiológica frente a micobactérias e fungos, o fato das Pastilhas de Paraformaldeído, nas condições do experimento, ter mostrado efetividade frente a 97.5\% dos esporos do Bacillus subtilis e 35\% dos Clostridium sporogenes pode-se inferir que as Pastilhas de Paraformaldeído a 0,5\%, sem aquecimento e uso de umidade adicional exposto a um período de $12 \mathrm{~h}$, apresentou indícios de ação desinfetante de alto nível.

\section{DISCUSSÃO}

São muitas as variáveis que interferem na esterilização a frio, com destaque para: temperatura, concentração do princípio ativo, umidade, tempo de exposição, $\mathrm{pH}$ e presença de matéria orgânica (16-17). A atividade germicida, usualmente aumenta com a elevação da temperatura, sendo $20^{\circ} \mathrm{C}$ a selecionada para a realização dos testes da Association of Official Analyptical Chemistis ${ }^{(12)}$. Nas autoclaves de formaldeído usadas em outros países, como a Inglaterra, o ciclo de esterilização é conduzido à temperatura de aproximadamente $70^{\circ} \mathrm{C}^{(18)}$

Com poucas excessões, nas quais o formaldeído não está incluído, o aumento da concentração do germicida intensifica sua eficácia e diminui o tempo necessário para a destruição microbiana ${ }^{(19)}$. A concentração de $0,5 \%$ escolhida neste estudo baseou-se nas condições mais utilizadas na prática.

O período de exposição para a esterilização por agentes químicos depende do material e do grau de contaminação, variando normalmente entre 4 e $18 \mathrm{~h}^{(8)}$. Entre os dois agentes alquilantes (formaldeído e glutaraldeído) o primeiro é o de ação bactericida mais lenta ${ }^{(20)}$.

Segundo Hoffman, Spiner ${ }^{(5)}$, a umidade relativa é, isoladamente, o fator mais importante que influencia na atividade dos gases esterilizantes, tais como o óxido de etileno e formaldeído por tornarem vulneráveis os microrganismos.

No Brasil, a regulamentação dos sanificantes e desinfetantes está a cargo da Vigilância Sanitária do Ministério da Saúde. É função do Instituto Nacional de Controle de Qualidade em Saúde (INCQS) da Fundação Oswaldo Cruz, a realização de análises toxicológicas, químicas e de comprovação da ação antimicrobiana para que o produto te- 
nha condições de ser registrado junto à Vigilância Sanitária. Conclui-se que, nas condições estabelecidas, com a metodologia adotada pelo INCQS, as pastilhas de paraformaldeído nas condições testadas apresentaram atividade desinfetante de alto nível. Os resultados obtidos podem contribuir para melhor fundamentar a sua utilização.

Em que pesem os referenciais e as tecnologias utilizadas neste estudo, o que realmente importa para a enfermagem e para os enfermeiros é a opção mais segura, definida no âmbito dos resultados apresentados neste trabalho, de poder utilizar na prática as pastilhas de Paraformaldeído, em condições de segurança aos clientes sob nossos cuidados que buscam o restabelecimento da saúde. Não é ético ser uma vítima de iatrogenia infecciosa tendo como fator de risco o inadequado processamento das artigos médicohospitalares.

\section{CONCLUSÕES}

O presente estudo permitiu chegar às seguintes conclusões:

-a avaliação "in vitro" da atividade antimicrobiana das Pastilhas de Paraformaldeído, segundo a metodologia da Association of Official Analyptical Chemistis, que foi realizada reproduzindo as condições mais freqüentes de uso nas Instituições de Saúde pesquisadas (com o emprego de $0,5 \%$ de Pastilhas de Paraformaldeído, sem o aquecimento e sem a adição da umidade relativa por um período de exposição de $12 \mathrm{~h}$ ) refutou a ação esterilizante. Houve recuperação de $65 \%$ dos esporos do Clostridium sporogenes (ATCC $\left.\mathrm{n}^{\circ} .3584\right)$ e $2,5 \%$ dos esporos do Bacillus subtilis (ATCC no 19659);

-a avaliação "in vitro" da atividade antimicrobiana das Pastilhas de Paraformaldeído, segundo o método de diluição de uso da metodologia da Association of Official Analyptical Chemistis, reproduzindo as condições mais freqüentes de uso nas Instituições de Saúde pesquisadas (com o emprego de 0,5\%, de Pastilhas de Paraformaldeído sem o aquecimento e sem a adição da umidade relativa por um período de exposição de $12 \mathrm{~h}$ ) apresentou resultados $100 \%$ satifatórios quanto à ação bactericida frente os microrganismos testes: Staphylococcus aureus (ATCC $n^{\circ} .6538$ ), Samonella choleraesuis (ATCC $n^{\circ} .10708$ ) e Pseudomonas aeruginosa ( $\left.A T C C n^{\circ} .15442\right)$;

- frente a estes resultados de avaliação microbiológica, pôde-se inferir que as Pastilhas de Paraformaldeído, nas condições mais freqüntes de uso nas Instituições de Saúde do Brasil (com o emprego de 0,5\% de Pastilhas de Paraformaldeído, sem o aquecimento e sem a adição da umidade relativa por um período de exposição de $12 \mathrm{~h}$ ) apresentaram indícios de atividade desinfetante de alto nível.

\section{REFERÊNCIAS}

(1) RutalaWA. APIC guideline for selection and use of disinfectants. Am J Infect Control 1990;18(2):99-117.

(2) Graziano KU, Silva A, Bianchi ERF. Métodos de proteção anti-infecciosa. In: Fernandes AT. Infecção hospitalar e suas interfaces na área da saúde. São Paulo: Atheneu; 2000. cap.11.

(3) Sociedade Brasileira de Enfermeiros de Centro Cirúrgico. Práticas recomendadas da SOBECC. São Paulo; 2000.

(4) Guia elaborada por enfermeiras brasileiras. recomendações práticas em processos de esterilização em estabelecimento de saúde, parteI: esterilização a calor. Campinas:Komedi, 2000.
(5) Hoffman RK, Spiner DR. Effect of relative humidity on the penetrability and sporicidal activity of formaldehyde. Appl Microbiol 1970;20(4):616-9.

(6) Mecke P. Desinfection and sterization of thermolabile instruments with gaseous formaldehyde.Zentralbl Bakteriol Mikrobiol Hyg. (B)1984;179(6):529-43.

(7) Newson SWB, Matheus J. Use and methods for testinfg formaldehyde sterilization. In: Collins $\mathrm{CH}$, Allwood MC, Bloomfield SF, Fox A. Desinfectants: their use and evaluation of effectiveness. London:Academic Press; 1981.p.61-76.
Atividade antimicrobiana das Pastilhas de Paraformaldeído reproduzindo as condições de uso nas Instituições de Saúde do Brasil 
Kazuko Uchikawa Graziano Luciene Figueiredo
(8) Brasil. Portaria n. 196 de 24 de julho de 1983. Dispõe sobre controle e prevenção de infecções hospitalares. In: Brasil Ministério da Saúde. Manual de controle de infecção hospitalar. Brasília, Centro de Documentação do Ministério da Saúde, 1985, p. 101-5.

(9) Zanon U, Neves J. Infecções hospitalares: prevenção diagnóstico e tratamento. Rio de Janeiro:Médica e Científica; 1987. p. 831-58.

(10) Graziano KU. Reutilização das Pastilhas de Paraformaldeído: avaliação da sua atividade esterilizante.[tese] São Paulo (SP): Escola de Enfermagem da Universidade de São Paulo ;1995.

(11) Brasil. Portaria n. 67 de 21 de fevereiro de 1985. Dispõe sobre "Normas complementares específicas para registro de saneantes domissanitários com ação antimicrobiana. Diário Oficial da União, Brasília, 27 fev. 1985a. Seção 1, p.3180-4.

(12) Association of official analytical chemists. Official method of anlysis of the Association of Official Analytical Chemists. 15.ed. Washington, 1995. p.65-77; Desinfectants.

(13) Romão CMPA, Miyazaki NHT, Silveira UM. Método para análise microbiológica de saneantes com ação antimicrobiana. In: Fundação Oswaldo Cruz. Instituto Nacional de Controle de Qualidade em Saúde. Manual de saneantes. Rio de Janeiro; 1987.
(14) Graziano KU. Avaliação da atividade esterilizante do paraformaldeído. [dissertação] São Paulo (SP): Escola de Enfermagem da Universidade de São Paulo;1989.

(15) Spaulding EH. Chemical disinfection of medical and surgical materials. In: Lawrence CA, Block SS. Disinfection, sterilization and preservation. $3^{\text {th }}$ ed. Philadelphia: Lea $\&$ Febiger; 1968. cap 32, p. 517-31.

(16) Crèmieux A, Fleurette J. Methods of testing desinfectants. In: Block SS. Desinfection, sterilization and preservation. $3^{\text {th }}$ ed. Philadelphia: Lea \& Febiger; 1983. cap.46, p.918- 45 .

(17) Kostenbauer HB. Physical factors influencing the activity of antimicrobial agents. In: Block SS. Desinfection, sterilization and preservation. $3^{\text {th }}$ ed. Philadelphia: Lea \& Febiger; 1983. cap.46, p.912-32.

(18) Alder VG. The formaldehyde low temperature steam steriling procedure. J Hosp Infect 1987;9(2):194-200.

(19) Shilling B, Wigert H, Weufffen W, Dobeberkau HJ. Use of paraformaldehyde tablets for bacterial count redution desinfection, cold sterilization and sterile preservation of medical instruments. Pharmazie 1982; 37(7):518-21.

(20) Schliesser T, Wiest JM. About the temperaturedependence of the bactericidal effect of some chemical desinfectants. Zentralbl Bakteriol [B] 1979;169(5-6): 560-6. 